\title{
ENIGE HYDROBIOLOGISCHE WAARNEMINGEN OP VLIELAND
}

DOOR

\author{
A. P. C. DE VOS
}

In Juni 1947 werden door mij in enige plasjes in de bosaanplant aan de Z.O.-kant van het eiland, in slootjes tussen de diverse bospercelen en in enige watertjes aan de Westkant (geen eendenkooien!) monsters genomen en wel op de volgende plaatsen:

I. IJsbaan achter het dorp Oostvlieland, Io VI

2. Plasje in het bos, ten $Z$. van het schelpenpad langs de Weekend-huisjes, ro VI

3. Visvijvertje, vlak bij vorig plasje, ro VI

4. Plasjes bij Vliehors, ten $Z$. van de grote weg, Ir VI

5. Plasje ten $Z$. van de grote weg iets meer naar Bomenland, I I VJ

6. Gat gevuld met water in hei achter Bomenland, I I VI

7. Slootje langs het fietspad naar Vianen, Z-kant, II VI

8. Vijvertje bij bank V.V.V. in buurt van Vuurtoren, I3 VI

9. Idem

Io. Slootje langs bospad, uitlopend op fietspad naar Vianen, I3 VI

II. Plas in bosjes bij de badweg, I6 VI

12. Plasje tussen Meeuwenduinen en het strand, $20 \mathrm{VI}$

De volgende dieren werden hier gevonden:

\section{VERMES}

Nais elinguis Müll. Oerst.; $N$. Josinae Vejdovsky; Slavina appendiculata (Udek.); Stylodrilus heringianus Clap.; Haemopis sanguisuga L.

\section{CRUSTACEEËN}

Cyclops viridis (Jurine); C. vernalis americanus Marsh.; $C$. agilis Koch, Sars; C. fimbriatus Fischer; Canthocamptus staphylinus (Jurine); C. pygmaeus Sars; Scapholeberis mucronata (O.F.M.); Simocepha'us vetulus (O.F.M.); Sim. exspinosus (Koch); Ceriodaphnia megops Sars; C. affinis Lillj.; Acroperus harpae Baird; Alona quadrangularis O.F.M.; Al. quadran- 


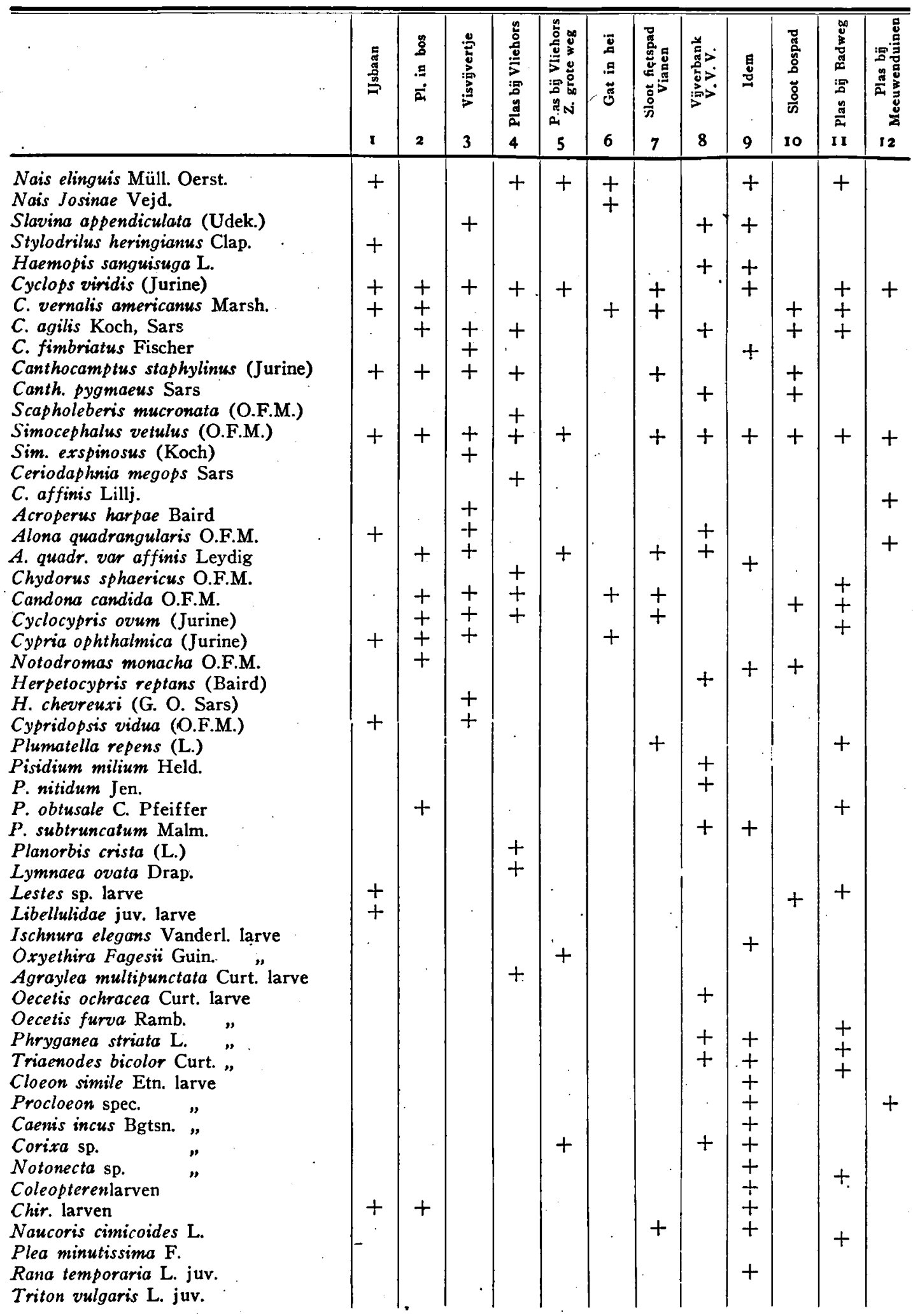


gularis var. affinis Leydig; Chydorus sphaericus O.F.M.; Candona candida O.F.M.; Cyclocypris ovum (Jurine); Cypria ophthalmica (Jurine) ; Notodromas monacha O.F.M.; Herpetocypris reptans (Baird); H. chevreuxi (G. O. Sars); Cypridopsis vidua (O.F.M.).

\section{MOLLUSKEN 1)}

Pisidium milium Held.; $P$. nitidum Jen.; $P$. obtusale C. Pfeiffer; $P$. subtruncatum Malm.; Planorbis crista (L.); Lymnaea ovata Drap.

\section{INSECTEN}

Larven van: Lestes sp.; Libellulidae; Ischnura elegans Vanderl.; Oxyethira Fagesii Guin., Agraylea multipunctata Curt.; Oecetis ochracea Curt.; Oecetis furva Ramb.; Phryganea striata L.;.Triaenodes bicolor Curt.; Cloeon simile Etn.; Procloeon spec.; Caenis incus Bgtsn.; Corixa en Notonecta spec; kever en Chir. larven. Volwassen insecten: Naucoris cimicoides L. en Plea minutissima $\mathrm{F}$.

Op enkele plaatsen kwam Plumatella repens (L.) voor. Tenslotte werden larven gevangen van Rana temporaria $\mathrm{L}$. en van Triton vulgaris $\mathrm{L}$.

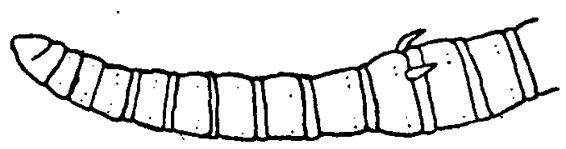

Fig. I. Stylodrilus heringianus Clap. Voorste lichaamsgedeelte.

De tabel toont de verspreiding der dieren over de verschillende vindplaatsen. De enige soort, die nieuw is voor de Nederlandse fauna, is de Oligochaet Styladrilus heringianus Clap. De kleur is roodachtig, de koplob is koepelvormig, vanaf het 4e segment bestat ieder lichaamssegment uit twee ringen, waarvan de grote achterste ring de borstels draagt. Deze, die in 4 rijen van 2 borstels zijn geplaatst, zijn onduidelijk gegaffeld of enkelvoudig. De $\sigma^{7}$ geslachtsopeningen liggen aan de top van niet terugtrekbare penissen op het roe segment.

I) De Pisidiën werden door de heer J. G. J. KuIPER, de overige schelpen door Mevrouw W. S. S. van der Feen-van Benthem Jutting gedetermineerd. 